\title{
Evaluation of an Early Three Phase Approach to Electric Circuit Instruction
}

\author{
https://doi.org/10.3991/ijep.v7i1.6418 \\ M.J. Turner \\ Purdue University, New Albany, IN, U.S.A. \\ MattTurner@Purdue.edu
}

\begin{abstract}
This paper presents a novel approach to the study of electric circuits: utilizing three phase electric power systems to introduce students to the techniques of circuit analysis beyond Kirchhoff's and Ohm's Laws. The efficacy of the pedagogy is evaluated by comparison of student performance on DC circuits assessment quiz pre and post intervention and by comparison to circuit analysis methods used by experts. Also discussed is how the curriculum affects student's qualitative and quantitative conceptions of the behavior of voltage and current in DC resistive circuits.
\end{abstract}

Keywords - Electric Circuit Analysis, Early Three Phase, Introductory Circuit Curriculum

\section{$1 \quad$ Introduction}

Electric circuit analysis is often used in Electrical and Computer Engineering and Technology (ECE/ECET) programs as an introductory course as it covers the fundamental principles and concepts which students will need in more advanced courses, and as such, is important to establishing a solid foundation for future courses. Unfortunately, the commonly employed "fundamentals only" approach of focusing on textbook style problem sets neglects developing students in other important ways such as: real-world contextual understanding of course material, long-term understanding and retention of subject matter, knowledge integration into existing schemas, meaningful engineering design experiences, and the development of soft skills such as communication, collaboration, and leadership. Therefore great interest exists in developing pedagogical methods to meet more well-rounded educational objectives that include 1) a rigorous and integrated curricular introduction to the discipline, 2) a clear linkage between core and advanced concepts within ECE/ECET, 3) an authentic connection to real-world applications, and 4) real-world relevant and technically appropriate design projects.

In an effort to address these issues, a variety of application based approaches have been implemented for introductory electrical engineering and engineering technology courses that put learning in context. Examples include replacing the introductory circuit course with analog signal processing [1], or designing new introductory courses around broad real world themes such as integrated sensing and information pro- 
cessing [2] or the programming of microcontrollers to integrate with peripherals [3], [4]. In all of these cases, the objective of the curricular re-design is to put classroom learning in a real-world context, with a goal of improving student learning of subject matter and better educating students on the linkage between concepts within ECE/ECET. Such methods have been shown to be effective in both engaging student interest and facilitating long-term understanding and retention of subject matter [1], [5]-[6].

As part of a recent re-design of the entire curriculum of the ECET program at Purdue University, similar evidence based pedagogical methods are being incorporated into much of the undergraduate curriculum, particularly in introductory courses. Part of this redesign was to introduce the techniques related to time-dependent circuit analysis in a new course; Modern Energy Systems (MES). MES implements learning in context by introducing time-dependent circuit analysis via the electric power system and its components. Reactive passive circuit elements are analyzed as properties of electric machines and other power system equipment (cables, load devices, transformers, etc.) and alternating current and voltage sources as the output of either an electric generator or transformer. This Early Three Phase method was designed to take concepts that are often nebulous to novice students (i.e. impedances and ideal sources) and correlate them to real devices, making it easier for students to integrate them into existing knowledge schemas. Additionally, because the circuits analyzed are three-phase, circuit analysis techniques such as the node voltage method, mesh currents, and superposition are taught in context of real-world applications, i.e. in radial distribution networks and in wye and delta circuit configurations.

However, the efficacy of this approach was untested, and an important question existed regarding student's abilities to generalize context specific learning to other applications: "can novice students take the knowledge from one ECET domain and successfully apply it to other related ECET areas?" This paper describes the application and assessment of this new Early Three Phase method as an approach to introducing the circuit analysis techniques beyond Ohm's law and Kirchhoff's laws, i.e. node voltage, mesh currents, and superposition. First, the implemented curricular structure of MES is clarified via comparison to traditional introductory circuit analysis course sequences. Second, student's abilities to transfer knowledge to other areas of ECET is analyzed via assessment data from a test of direct current resistive electric circuit and power concepts. This test compares the solution methods utilized by students to solve DC networks both before and after taking the MES course. Finally, student solution methods on this test are compared to the methods utilized by a panel of experts as a measure of change in the sophistication of the students' circuit analysis skills.

\section{Early Three Phase Approach}

Commonly, introductory circuit analysis is taught using either a one-semester or two-semester course sequence in the sophomore year [7], [8], as summarized in Table 1 . 
Table 1. Representative topic organization for one and two semester electric circuit analysis courses.

\begin{tabular}{|c|c|c|}
\hline \multirow{2}{*}{1 Semester } & \multicolumn{2}{|c|}{2 Semesters } \\
\hline & Semester 1 & Semester 2 \\
\hline Voltage, Current, Power and Energy & $\begin{array}{l}\text { Voltage, Current, Power and } \\
\text { Energy }\end{array}$ & Power Calculations \\
\hline $\begin{array}{l}\text { Sources, Ohm's Law, Kirchhoff's } \\
\text { Laws }\end{array}$ & $\begin{array}{l}\text { Sources, Ohm's Law, Kirchhoff's } \\
\text { Laws }\end{array}$ & Balanced Three Phase Circuits \\
\hline DC Resistive Circuits & DC Resistive Circuits & S-Domain Circuit Analysis \\
\hline Circuit Analysis Techniques & Circuit Analysis Techniques & Filters \\
\hline Inductance and Capacitance & Inductance and Capacitance & Operational Amplifiers \\
\hline Response of RLC Circuits & Response of RLC Circuits & $\begin{array}{l}\text { Applications of the Fourier } \\
\text { Transform }\end{array}$ \\
\hline Sinusoidal Waveforms and Phasors & $\begin{array}{l}\text { Sinusoidal Waveforms and Phas- } \\
\text { ors }\end{array}$ & Two-Port Networks \\
\hline Sinusoidal Steady-State Analysis & Sinusoidal Steady-State Analysis & \\
\hline Power Calculations & & \\
\hline $\begin{array}{l}\text { Optional Topics: } \\
\text { - Op-Amps } \\
\text { - Balanced Three Phase Circuits } \\
\text { - S-Domain Circuit Analysis } \\
\text { - Frequency Selective Circuits } \\
\text { - Two Port Networks }\end{array}$ & & \\
\hline
\end{tabular}

Sequences such as these are typically not designed to address the broader educational objectives previously identified, and often the instruction focuses on mathematical analysis of circuit models, with any connection to real-world engineering experiences attempted via the use of "application type" examples.

Purdue ECET's legacy plan of study followed this common method, starting in the first semester of the freshman year with Introduction to Circuit Analysis, a four credit algebra-based introductory circuit analysis course and lab. This course utilized an approach similar to that presented in the 1 Semester sequence of Table 1. Other first semester courses included a three credit digital systems fundamentals and a two credit gateway course on the proper use of basic tools and circuit construction techniques. Field/specialty specific content was not introduced to students until the fourth semester, beginning with required four credit courses in power electronic amplifiers and three-phase systems, electric machines, and programmable logic controllers. The complete legacy plan of study is presented in Table 2. As part of the curricular re-design, the content covered in the legacy introductory sequence was replaced with a curriculum that emphasizes learning in context. In semester one, students take a three credit gateway course, Gateway to ECET, that introduces them to the academic and professional field of electrical and computer engineering technology, as well as foundational electrical principles as applied in familiar applications of technology that impact society. Circuit analysis is then taught via a two course sequence: Data Acquisition and Systems Control (DASC) and MES. In the DASC course, fundamental electrical parameters and measurement techniques are introduced. These are then applied to implementing power switches, amplifiers, actuators and sensors. In the MES course, the electric grid and its components are used to study steady state circuit analysis and advanced circuit analysis techniques as applied to three-phase systems, circuits contain- 
ing transformers, and typical transmission and distribution circuits. Via this arrangement, student's first introduction to AC systems is in the DASC course: AC waveforms are introduced as signals that are transduced from a sensor into a voltage waveform and are the electrical input to amplifier systems. Then, the bulk of instruction on AC circuit analysis techniques is provided to students in MES. Although not the focus of this paper, a two course digital circuit fundamentals sequence was also implemented as part of the re-designed curriculum, which is summarized in Table 2.

Comparison of the two plans of study presented shows that in the re-designed curriculum, three-phase content is taught one semester earlier than in the legacy curriculum and with significantly fewer preparatory ECET courses: three in the re-designed plan as compared to seven in the legacy plan. The re-designed plan of study is therefore not simply a re-ordering of the course sequence, and is instead a change to the traditional hierarchy that topics within ECET are taught. Although a complete description of the re-designed ECET curriculum is beyond the scope of this article, Table 3 provides the curricular topics chosen for inclusion in the three introductory courses that cover electric circuit analysis. While the topics in both DASC and MES are commonly found in ECE/ECET curriculums, their incarnation at Purdue is a significant departure from traditional methods in that they are introduced to students much earlier in the curriculum, and that they are designed to simultaneously provide a system level view of electrical and electronic applications (e.g. control and electric power) and fundamental

Table 2. Comparison of Legacy and Re-designed Plans of Study for ECET

\begin{tabular}{|c|c|c|c|}
\hline \multicolumn{2}{|c|}{ Legacy Plan of Study } & \multicolumn{2}{|c|}{ Re-designed Plan of Study } \\
\hline $\begin{array}{l}\text { Semester } 1 \\
\text { - Introduction to Circuit } \\
\text { Analysis (4) } \\
\text { - Digital Systems Funda- } \\
\text { mentals (3) } \\
\text { - Exploring EET (2) }\end{array}$ & $\begin{array}{l}\text { Semester } 2 \\
\text { - Electronic Circuit } \\
\text { Analysis (4) } \\
\text { - Digital Applica- } \\
\text { tions (3) }\end{array}$ & $\begin{array}{c}\text { Semester } 1 \\
\text { - Gateway to EET (1) }\end{array}$ & $\begin{array}{l}\text { Semester } 2 \\
\text { - Data Acquisition and } \\
\text { System Control (3) } \\
\text { - Introduction to Digital } \\
\text { Systems (3) }\end{array}$ \\
\hline $\begin{array}{l}\text { Semester } 3 \\
\text { - AC Electronic Circuit } \\
\text { Analysis (4) } \\
\text { - Introduction to Micropro- } \\
\text { cessors (4) }\end{array}$ & $\begin{array}{c}\text { Semester 4 } \\
\text { - } \text { Power and RF } \\
\text { Electronics (4) } \\
\text { - Electrical Power } \\
\text { and Controls (4) } \\
\text { - Electronic System } \\
\text { Design and Fabri- } \\
\text { cation (4) }\end{array}$ & $\begin{array}{l}\text { Semester } 3 \\
\text { - Professional and } \\
\text { Career Development } \\
\text { (1) } \\
\text { - DC and Pulse Elec- } \\
\text { tronics (3) } \\
\text { - Concurrent Digital } \\
\text { Systems (3) } \\
\text { - Modern Energy } \\
\text { Systems (3) }\end{array}$ & $\begin{array}{l}\text { Semester 4 } \\
\text { - Electronics Prototype } \\
\text { Development and Con- } \\
\text { struction (3) } \\
\text { - Wireless Communication } \\
\text { (3) } \\
\text { - ECET Sophomore Elec- } \\
\text { tive (3) }\end{array}$ \\
\hline $\begin{array}{l}\quad \text { Semester } 5 \\
\text { - Intro to Communication } \\
\text { Systems (4) } \\
\text { - Analog Signal Processing } \\
\text { (4) } \\
\text { - ECET Elective (4) }\end{array}$ & $\begin{array}{l}\text { Semester 6 } \\
\text { - Project Develop- } \\
\text { ment \& Manage- } \\
\text { ment (4) } \\
\text { - ECET Elective (4) } \\
\text { - ECET Elective (4) }\end{array}$ & $\begin{array}{c}\text { Semester } 5 \\
\cdot \text { ECET Elective (3) } \\
\text { - ECET Elective (3) }\end{array}$ & $\begin{array}{l}\text { Semester } 6 \\
\text { - ECET Elective (3) } \\
\text { - Global Professional } \\
\text { Issues in EET (3) }\end{array}$ \\
\hline $\begin{array}{l}\text { Semester } 7 \\
\text { - Project Design and De- } \\
\text { velopment, Phase } 1(1) \\
\text { - Professional Issues (1) } \\
\text { - ECET Elective (4) }\end{array}$ & \begin{tabular}{l}
\multicolumn{1}{c|}{ Semester 8} \\
- Project Design and \\
Development, \\
Phase 2 (1)
\end{tabular} & $\begin{array}{l}\text { Semester } 7 \\
\text { - Electrical and Elec- } \\
\text { tronics Product and } \\
\text { Program Manage- } \\
\text { ment (3) } \\
\text { - ECET Elective (3) }\end{array}$ & $\begin{array}{l}\text { Semester } 8 \\
\text { - Project Design and De- } \\
\text { velopment (3) } \\
\text { - ECET Elective (3) }\end{array}$ \\
\hline
\end{tabular}


electrical circuit analysis instruction. For example, Figure 1 presents a common WyeWye three phase circuit configuration utilized in electric power systems. This circuit is utilized in MES to both introduce real-world three-phase topologies and to have students learn and apply the circuit analysis techniques of node voltage, mesh current, and superposition. The voltage source circuit is introduced as the output of a threephase generator, and the load circuit as representing an industrial lighting load. Students are asked to calculate the voltage at node $\mathrm{X}$ using the node voltage method, to calculate the current through R2 by applying the mesh current method, and to determine the current flow through R3 due to source V2 only using superposition. Therefore, the use of one three-phase circuit enables instruction on all three techniques in a real world context.

Table 3. Topic organization for introductory ECET Circuit Analysis curriculum

\begin{tabular}{|l|l|l|}
\hline \multicolumn{1}{|c|}{ Gateway to ECET } & \multicolumn{1}{|c|}{ DAQ and System Control } & \multicolumn{1}{c|}{ Modern Energy Systems } \\
\hline Scientific Notation & $\begin{array}{l}\text { System Parameters and Specifica- } \\
\text { tions }\end{array}$ & $\begin{array}{l}\text { RMS, Peak, and Peak-to Peak } \\
\text { Quantities }\end{array}$ \\
\hline DC Current and Voltage & Thevenin and Norton Equivalents & Inductance and Capacitance \\
\hline Resistance & Operational Amplifiers & Steady State Phasor Analysis \\
\hline Ohm's Law, Power, and Energy & Op-Amp Circuits & Real and Reactive Power \\
\hline Series and Parallel Circuits & Filters & Three Phase Circuit Topologies \\
\hline $\begin{array}{l}\text { Branch Current Analysis of } \\
\text { Series-Parallel Circuits }\end{array}$ & Power Amplifiers & Balanced and Unbalanced Circuits \\
\hline AC Waveforms & Diodes and Rectifiers & $\begin{array}{l}\text { Node Voltage, Mesh Current, and } \\
\text { Superposition }\end{array}$ \\
\hline Amplifiers & Motors and PWM Control & Transformers \\
\hline & Continuous Control & Electric Cable \\
\hline & Closed Loop Control & Electric Distribution Systems \\
\hline
\end{tabular}

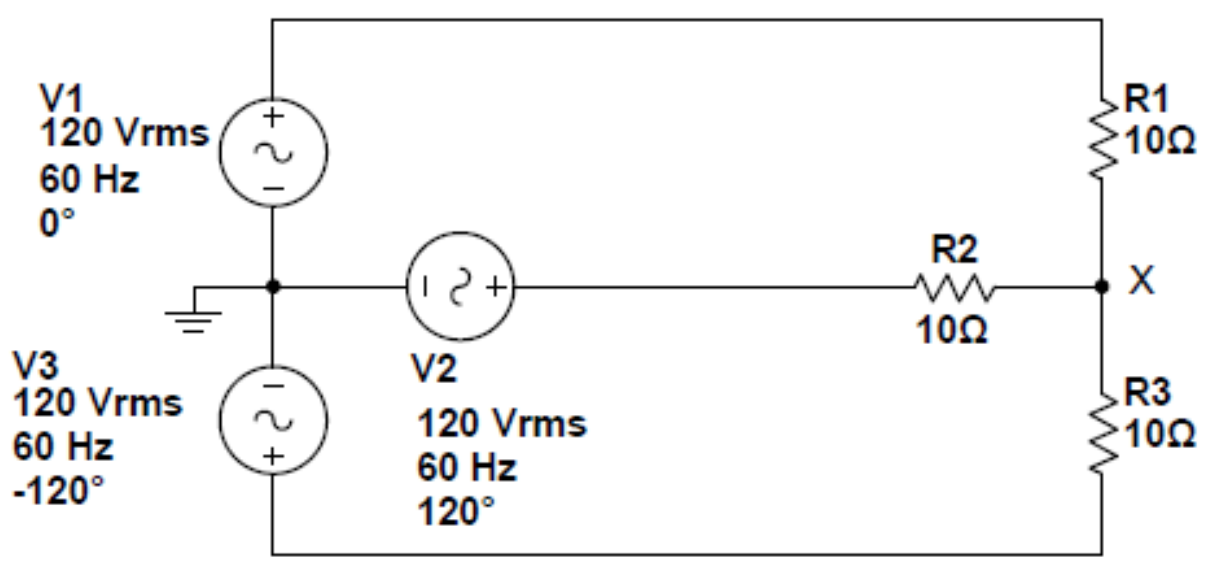

Fig. 1. Three phase circuit for instruction on node voltage, mesh current, and superposition methods. 
Due to the unique approach required of MES to both $\mathrm{AC}$ analysis and electric power system instruction, no appropriate textbook or lab manual could be identified from publishers that was suitable to inform course design in a manner that achieved the instructional objectives of the course. Instead, a hybrid-flipped course was developed around a digital media textbook written by the course instructor specifically for MES. The text utilizes a combination of traditional written material and short embedded/hyperlinked video lectures. Prior to class, students are assigned to complete chapters from the text, which include a reading and video assignment, open-ended qualitative discussion questions, and quantitative circuit analysis problems. An online multiple choice quiz is also included with each chapter as a gating activity to encourage completion. The two weekly 50-minute class meetings are spent on small group discussions and team-based problem solving related to the chapter assignments. Under this instructional method, the instructor serves less as a traditional lecturer and more as a facilitator/coach of student-driven discussion groups and cooperative group problem solving. The course also utilizes a media supported homework model: step-bystep solutions to all homework problems are provided to students in video format. Additionally, MES has a laboratory component of 1 hour and 50 minutes per week, with approximately 13 hands-on lab experiments performed each semester. Table 4 provides a schedule of course topics in the lecture and lab.

\section{Evaluation}

One of the primary goals of the curriculum re-design was to improve student's achievement of learning outcomes by placing learning in context of real world applications. Examples of fundamental student misconceptions that have been observed include that: current is consumed in circuits [9], current divides into two equal parts at all circuit junctions [10], batteries maintain a fixed current regardless of load [11], batteries in parallel provide more voltage [12], and students have problems identifying the important topological aspects of circuits [13]. In addition to qualitative misconceptions regarding the behavior of DC resistive electric circuits, students often make quantitative circuit analysis mistakes, including: incorrectly labeling voltage polarities and current directions, simplifying circuits incorrectly, formulating and solving node voltage equations incorrectly, formulating and solving mesh currents incorrectly, and applying and solving via superposition incorrectly. It was hoped that the study of real world systems would help to reduce such errors by developing a functional understanding, i.e. that "real" world understanding would transfer to their mathematical analysis of circuits [14].

The purpose of this study is to evaluate the effect of the Early Three Phase Approach on the DC circuit analysis skills of students in rectifying many of the common errors previously identified in [9]-[13], particularly relating to the application of the major techniques of circuit analysis: node voltage, mesh current, and superposition. In this section, we report on the analysis of the Early Three Phase method via the use of a DC concepts inventory assessment tool. Such tests are widely utilized as tools to investigate student understanding as it relates to electrical circuits [15]. 
Table 4. Topic Schedule for Modern Energy Systems Course

\begin{tabular}{|c|c|c|}
\hline Category & Course Topic & Lab Topic \\
\hline $\begin{array}{l}\text { Fundamentals } \\
\text { of Electric } \\
\text { Energy Con- } \\
\text { version }\end{array}$ & $\begin{array}{l}\text { - Overview of Energy Systems } \\
\text { - Work, Energy, Force and Power } \\
\text { - Electric Energy Supply and Consumption } \\
\text { Growth Rates } \\
\text { - Electrical Energy Conversion Technologies } \\
\text { - Electric Power Systems }\end{array}$ & $\begin{array}{l}\text { - Lab 1: AC Circuits Review } \\
\text { - Lab 2: Fuel to Electricity } \\
\text { - Lab 3: Power Plant Tour }\end{array}$ \\
\hline $\begin{array}{l}\text { Fundamentals } \\
\text { of AC Power }\end{array}$ & $\begin{array}{l}\text { - AC Quantities as Phasors } \\
\text { - Phasor Analysis of Passive Circuit Elements } \\
\text { - Single Phase AC Power } \\
\text { - Three-Phase Circuits } \\
\text { - Balanced Three Phase Power Calculations }\end{array}$ & $\begin{array}{l}\text { - Lab 4: Phasor Diagram for RLC } \\
\text { Circuit } \\
\text { - Lab 5: Single Phase Power }\end{array}$ \\
\hline AC Generation & $\begin{array}{l}\text { - Synchronous Machine Operation } \\
\text { - Generator Terminal Characteristics } \\
\text { - Thermal Energy Conversion: Steam Processes } \\
\text { - Thermal Energy Conversion: Combustion } \\
\text { Processes } \\
\text { - Mechanical Energy Conversion: Hydro } \\
\text { - Mechanical Energy Conversion: Wind } \\
\text { - Solar PV and Inverters }\end{array}$ & $\begin{array}{l}\text { - Lab 6: Balanced Three Phase } \\
\text { Voltage/Current } \\
\text { - Lab 7: Terminal Performance of } \\
\text { Synchronous Machine } \\
\text { - Lab 8: Wind Turbines }\end{array}$ \\
\hline Electric Loads & $\begin{array}{l}\text { - Load Types and Load Models } \\
\text { - Power Factor Correction } \\
\text { - Battery Energy Storage as Load and Supply } \\
\text { - Load Profiles }\end{array}$ & - Lab 9: Solar PV and Inverters \\
\hline $\begin{array}{l}\text { Transmission } \\
\text { and Distribu- } \\
\text { tion }\end{array}$ & $\begin{array}{l}\text { - Representation of Transmission and Distribu- } \\
\text { tion Lines } \\
\text { - Electrical Characteristics of Conductors } \\
\text { - Short, Medium, and Long Line Models } \\
\text { - Power Flow Through A Transmission Line }\end{array}$ & $\begin{array}{l}\text { - Lab 10: AC Induction Motor } \\
\text { Characteristics and VFDs }\end{array}$ \\
\hline $\begin{array}{l}\text { Power Trans- } \\
\text { formers }\end{array}$ & $\begin{array}{l}\text { - Ideal Transformer } \\
\text { - Practical Transformer } \\
\text { - Three Phase Transformer }\end{array}$ & $\begin{array}{l}\text { Lab 11: Voltage Drop in a Trans- } \\
\text { mission Line and Power Factor } \\
\text { Correction }\end{array}$ \\
\hline $\begin{array}{c}\text { System Opera- } \\
\text { tion }\end{array}$ & $\begin{array}{l}\text { - Overview of Interconnected Power System and } \\
\text { Economic Dispatch } \\
\text { - Overview of Smart Grids and Distributed Gen- } \\
\text { eration } \\
\text { - Overview of Power Flow in Power System } \\
\text { Networks } \\
\text { - Overview of Power Quality }\end{array}$ & $\begin{array}{l}\text { - Lab 12: Transformer Characteris- } \\
\text { tics } \\
\text { - Lab 13: Unbalanced Three Phase } \\
\text { System and Multiple Generator } \\
\text { System }\end{array}$ \\
\hline
\end{tabular}

\subsection{Method}

The sample population was divided between experts and students. The expert group included ten electrical engineering technology faculty from a major research university in the United States. The student group included eight students enrolled in the experimental course offering described previously. Thus the samples represented both experts and novices in electrical circuit analysis. The student group was tested both prior to enrollment in (i.e. pre-test) and after completion of the MES course (i.e. post-test). 
The questionnaire presented to the students consisted of six qualitative open ended response questions and one quantitative circuit analysis exercise. The expert's questionnaire was of the same quantitative circuit analysis exercise. The qualitative questionnaire was used to deduce functional relationships between student knowledge of DC circuit analysis principles related to KVL, KCL, Ohm's Law, and power in electric circuits. The quantitative questionnaire was used to identify the solution methods used in solving typical DC circuit problems. Both questionnaires are included as Figure 2.

\subsection{Qualitative Assessment Questionnaire}

The qualitative questionnaire is designed such that students solve the circuit using functional concepts rather than mathematical equations. Because it does not include any numerical values for components or sources, the circuit must be analyzed by applying a general understanding of the principles of KVL, KCL, and Ohm's law, and not simply by "number crunching". Specifically:

- Item a) of the assessment tests the understanding of a short circuit and the effects of a short on non-shorted circuit elements. The correct solution begins by identifying that a short circuit effectively removes the lightbulb X3 from the circuit. Once the bulb is removed, two different approaches can be used: light intensity is related to voltage, which increases for both X1 and X2 (an application of KVL), or light intensity is related to current, which increases for both X1 and X2 (an application of Ohm's Law). More advanced students may correctly relate light intensity to power, and identify that both $\mathrm{I}$ and $\mathrm{V}$ increase for $\mathrm{X} 1$ and $\mathrm{X} 2$, resulting in an increase in light intensity.

- Item b) tests the understanding of the current and voltage changes caused by applying a short circuit condition to a circuit element. The correct solution can be arrived at by either identifying that by shorting the terminal of the light bulb together no current flows through the bulb, or by identifying that by shorting the element the potential difference across the bulb is $0 \mathrm{v}$.

- Item c) tests the concept that the current delivered to the bulbs comes from the battery and that a short circuit causes an increase in current. For students who utilized Ohm's law in solving itema), the question tests consistency of their solution approach. For students who utilized KVL in solving itema), the question tests their ability to apply Ohm's Law.

- Item d) tests the application of KVL to the circuit. For students who utilized Ohm's law in solving item a), the question tests their ability to apply KVL. For students who utilized KVL in solving item a), the question tests consistency of their solution approach.

- Item e) tests the concept of power dissipation in circuit elements. The correct solution begins by identifying that no power is delivered to a shorted circuit element $\mathrm{X} 3$, since both I and $\mathrm{V}$ are 0 . The change in power dissipated in bulbs X1 and X2 can be derived by noting that both current and voltage increase, and therefore power increases via $\mathrm{P}=\mathrm{IV}, \mathrm{P}=\mathrm{I} 2 \mathrm{R}$ or $\mathrm{P}=\mathrm{V} 2 / \mathrm{R}$.

- Item $\mathrm{f}$ ) tests the concept of power conservation, and can be solved by identifying that any power dissipated in the circuit must come from the battery source. 


\subsection{Quantitative Assessment Questionnaire}

The quantitative assessment shown in Figure 2 is open ended, requiring students to determine circuit parameters. Primarily, the assessment was used to evaluate which circuit analysis methods students applied to the circuit and how accurately the methods were applied. Additionally, the assessment tests the same concepts as the quantitative survey, but using numerical analysis rather than qualitative reasoning. This enables analysis of student consistency between numerical and conceptual analysis of DC resistive concepts.
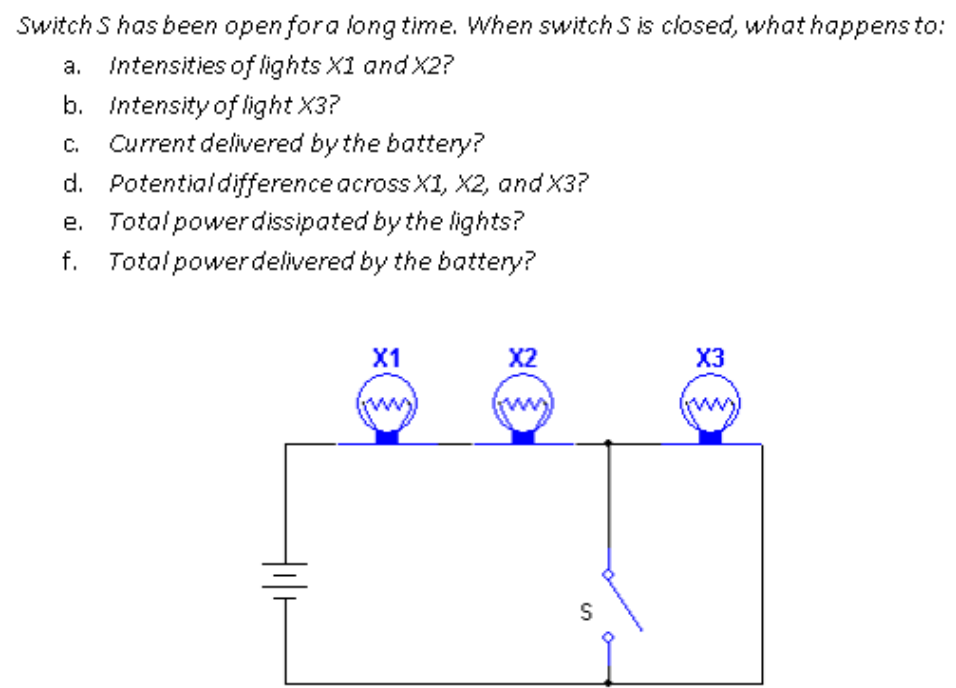

For the following circuit, calculate:

a. Current flow through the $4 \Omega$ resistor.

b. Totalpowersourced by the $8 \mathrm{~V}$ supply.

c. Potentialdifference (voitage drop) between points $P$ and $Q$.

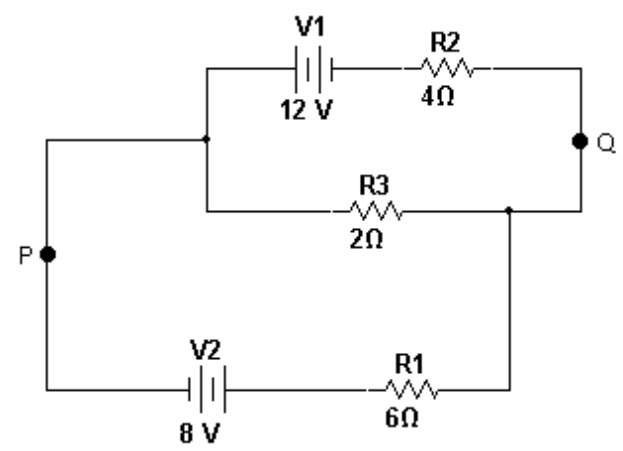

Fig. 2. DC concepts inventory qualitative and quantitative questionnaires. 


\section{$4 \quad$ Results}

\subsection{Qualitative Questionnaire Pre-Test Analysis}

Table 5 summarizes the results of the pre-test qualitative study. Student scores on the overall assessment ranged from $0 \%$ to $100 \%$, with an average score of $50 \%$ over the entire assessment. Individual item scores are also reported in Table 5, as the percentage of students choosing correct responses to each question.

In response to item a, incorrect responses were: "remains the same" $(n=3)$, indicating that many students either do not connect light intensity to current through the bulbs / voltage across the bulbs, or do not recognize that a change in these quantities occurs when the X3 load is shorted.

In response to item $b)$, incorrect responses were: "decreases" $(n=2)$ and "stays the same" $(\mathrm{n}=1)$. When considered in context of questionnaire item a, the response decrease indicates that students think that the voltage or current is "diverted" by the short, with some being applied to the short itself and some being applied to the circuit element that is shorted. The response "stays the same" indicates that students do not connect the concept of short circuit to zero voltage or zero current to the shorted element. Although not tested by this survey, this may indicate that students do not connect the concept of a short to $0 \Omega$ of resistance.

In response to item c), incorrect responses were: "decreases" $(\mathrm{n}=2)$ and "remains the same" $(\mathrm{n}=3)$. The response decrease indicates that students incorrectly apply

Ohm's law, or do not recognize that the short removes load, increasing resistance. This is indicative of the idea that load devices "consume current" and therefore a reduction in load results in a reduction of current. The response "remains the same" indicates that students see the battery as a constant source of current, independent of the load connected. The increase in the number of incorrect responses to item c indicates that although most student correctly identify the effect of the short circuit on luminous intensity, they demonstrate less ability to correctly identify the cause of the change.

In response to item d), incorrect responses were: "remains the same" $=5$. This response indicates that students incorrectly applied KVL to the modified circuit, failing to recognize that the battery voltage is distributed across $\mathrm{X} 1$ and $\mathrm{X} 2$ only, and demonstrating that students have misconceptions related to potential difference.

In response to item $\mathrm{f}$, incorrect responses were: decreases $=3$, remains the same $=2$. Although the number of incorrect responses to item $\mathrm{f}$ was the same as to item 3 , the distribution of responses differed. In considering consistency between responses, most students ( 7 out of 8 ) demonstrated understanding that the power consumed by the load must equal the power delivered by the battery. Only one student indicated the inconsistent statement regarding conservation of power, i.e. that circuit power remains the same while battery power decreases. 


\subsection{Qualitative Questionnaire Post-Test Analysis}

Post-test scores of the qualitative questionnaire, as summarized in Table 5, indicate substantial improvement to students reasoning abilities and qualitative analysis of electric circuits, with an increase of an average score of $50 \%$ to $77 \%$ accuracy for the overall test. Individual scores for each item also increased for all items. Although all item scores increased, the score for item d, related to the change in potential difference across the three bulbs when one is shorted, still scored low, indicating a persistent misunderstanding of the application of KVL to the circuit. In contrast, relatively large gains were made in the score for items e) and f), relating to the ability of students to consider the effects of multiple variables simultaneously, and indicating improved understanding of the application of $\mathrm{P}=\mathrm{IV}$.

\subsection{Expert Responses to Quantitative Questionnaire}

As a standard of comparison 10 electrical engineering expert respondents were asked to complete the quantitative quiz. Table 6 summarizes the solution methods that were applied.

Most experts began by re-drawing the circuit in order to more clearly identify the nodes of the circuit. At this step, all of the expert respondents who redrew the circuit also intuitively added a ground node to the circuit, most commonly at node P. A common representation of the re-drawn circuit is depicted in Figure 3. All experts then selected and applied a single solution method to the circuit in order to either solve for the voltage at the nodes or the currents in the branches. The majority of respondents utilized either mesh current or node voltage. In the mesh current technique (aka loop currents), unknown currents are assigned to loops, and the sum of the

Table 5. Student scores (percent) to qualitative test

\begin{tabular}{|c|c|c|c|c|c|c|c|}
\cline { 2 - 8 } & \multirow{2}{*}{ Average Score (SD) } & \multicolumn{5}{|c|}{ Percent Correct Per Test Item } \\
\cline { 3 - 8 } & & $\boldsymbol{A}$ & $\boldsymbol{B}$ & $\boldsymbol{C}$ & $\boldsymbol{D}$ & $\boldsymbol{E}$ & $\boldsymbol{F}$ \\
\hline Pre-Test $(\mathrm{n}=8)$ & $3 / 6(2.3)$ & 62.5 & 62.5 & 37.5 & 37.5 & 37.5 & 37.5 \\
\hline Post-Test $(\mathrm{n}=7)$ & $4.6 / 6(1.2)$ & 85.7 & 85.7 & 85.7 & 57.1 & 71.4 & 71.4 \\
\hline
\end{tabular}

Table 6. Solution methods to quantitative Test

\begin{tabular}{|c|r|r|r|}
\hline \multirow{2}{*}{ Solution Method } & \multicolumn{3}{|c|}{ Population } \\
\cline { 2 - 5 } & \multicolumn{1}{|c|}{ Experts (n=10) } & Student Pre-Test (n=8) & \multicolumn{1}{c|}{ Student Post-Test (n=7) } \\
\hline Mesh Currents & 3 & 0 & 3 \\
\hline Node Voltages & 3 & 0 & 3 \\
\hline Super Position & 2 & 0 & 0 \\
\hline Branch Currents & 1 & 4 & 1 \\
\hline Norton Equivalent & 1 & 0 & 0 \\
\hline Unidentifiable & 0 & 4 & 7 \\
\hline Redrew Circuit & 6 & 5 & 83 \\
\hline Average Score & 100 & 61 & 0 \\
\hline
\end{tabular}




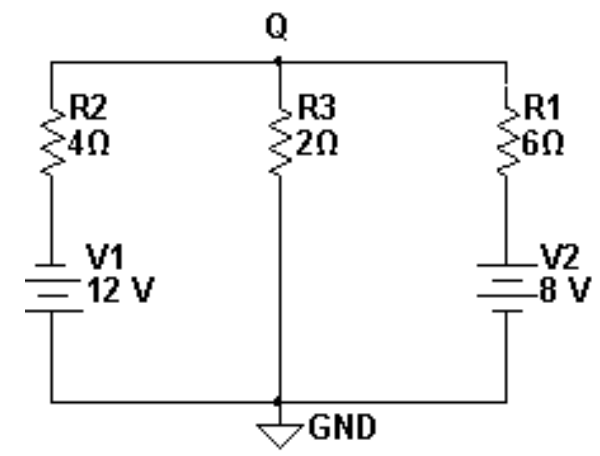

Fig. 3. Re-drawn circuit to emphasize common nodes and choose ground reference point.

voltages around the loops are solved using Kirchhoff's Voltage Law. In the node voltage technique, unknown voltages are assigned to nodes, and the sum of the currents into the nodes are solved using Kirchhoff's Current Law. The 3rd most popular solution method was the use of superposition, in which all but one of the sources in the network are eliminated, and the network is solved using series and parallel circuit reduction techniques. The technique is repeated for each source in the circuit, and the final solution is determined by summing (superimposing) the results of each iteration.

Although it is the 1 st technique taught to most electrical engineering students, only one expert respondent solved the circuit through the application of the branch current method, in which the full set of KVL and KCL equations are written for the unknown voltage and current values. Finally, one of the expert respondents chose to reduce the network to a Norton equivalent circuit, using the resistor R2 as the load for analysis. The general solution approach of an expert can therefore be summarized as: 1) redraw circuit to clarify nodal relationships and assign a circuit ground. 2) Apply a standard solution technique from circuit analysis to solve for either branch currents or node voltages. 3). Use the solved for variables to answer the questions posed on the concepts inventory.

\subsection{Quantitative Questionnaire Pre-Test Analysis}

The average score on the quantitative pre-test was $61 \%$, with none of the students surveyed correctly analyzing the circuit presented in Figure 1. Five of the students began by re-drawing the circuit to more clearly identify the circuit nodes. Four of these five then proceeded to apply a standard solution method to the circuit, all of them choosing the branch current method. The most common reason that circuit was not correctly solved was failing to account for the polarity of voltage source V1 in the branch current calculations (i.e. IR2 $=(\mathrm{VQ}+12) / 4)$. For those students who did not apply a valid solution method, incorrect methods were: inappropriately combining series and parallel resistor to form a Thevenin equivalent circuit without the application of superposition $(n=2)$, and no-discernable solution method presented $(n=2)$. Other common errors include incorrectly solving currents through resistors based on node potentials as related to ground and not across elements. Regarding the specific 
questions on the survey, all students applied a valid solution method to solve for $I_{R 4}$ once the other circuit parameters had been solved for. Two students incorrectly attributed the power absorbed by R1 to the total power sourced by V2. Finally, most students calculated the potential difference between points $\mathrm{P}$ and $\mathrm{Q}$ by assigning point $\mathrm{P}$ as ground in their solution method. However, three students did not address this question, indicating they could not apply the concept of potential difference abstractly.

\subsection{Quantitative Questionnaire Post-Test Analysis and Comparison to Expert Solutions}

The average score on the post-test was $83 \%$, with two students correctly solving for all of the circuit parameters. All of the students in the post-test case began their solution methods by re-drawing the circuit to identify circuit nodes, and all applied a standard solution to solve for circuit parameters: mesh currents (3), node voltage (3), and branch current (1). Although most students solved the circuit correctly, some errors were common in the circuit solutions. Frequently students failed to properly account for the voltage polarity of the sources when constructing the node voltage equations or when solving mesh current $(\mathrm{n}=2)$. Other errors were related to mistakes in algebraic manipulation of the circuit equations $(\mathrm{n}=2)$ and quantitative mathematical errors $(n=1)$. Regarding the specific items of the survey, all students applied a valid solution method to solve for IR4 once the other circuit parameters had been solved for. Unlike the pre-test, all students calculated power using the voltage and current of the $8 \mathrm{~V}$ source V2. In calculating VPQ, all students presented solutions that were consistent with their mathematical calculations for the circuit parameters, indicating an understanding of the concept of potential difference.

Student circuit solutions to the post-test questionnaire are very similar to the solutions presented by the expert respondents in general approach. In both cases, the primary techniques utilized were to redraw the circuit to better identify common nodes and to select a standard solution method from node voltage, mesh current, branch current, superposition, or Norton equivalent. However, in contrast to the experts who demonstrated each of these techniques, no student responses utilized superposition or Norton Equivalent. One aspect of the expert solutions that deserves specific mention is the intuitive application of KVL. In all of the solutions submitted, voltages at nodes were solved for by applying KVL to loops that did not directly contain circuit components. For example, the voltage across R1 in Figure 1 can easily be solved for by applying $\mathrm{KVL}$ as $\mathrm{VQ}=\mathrm{VR} 1+\mathrm{V} 2$. Such loops are not often obvious to novice students.

\section{Conclusions and Implications}

Results from the pre-test confirm findings from previous studies that even after instruction, novice students have difficulty applying the concepts of KVL, KCL, and Ohm's Law to electric circuit analysis. When comparing qualitative and quantitative approaches, it is clear the students are not very consistent in their reasoning, and are 
often of two distinct approaches: a mathematical approach in which circuit equations are applied (often incorrectly) to solve quantitative problems and a consumption approach in which current and voltage are viewed as consumed quantities within a circuit to solve qualitative problems.

Comparison of the pre and post test scores and solution methods support that our Early Three Phase approach to circuit analysis instruction helps to rectify many of the inconsistencies and analysis errors that are commonly displayed by novice students when solving electric circuits. In particular, the method shows achievement in both having students adopt the analysis methods and techniques commonly employed by experts and in correctly solving for unknown circuit variables of current and voltage. Although this method has not been compared against a traditional 2-semester course in circuit analysis, it at worst does no harm, and at best achieves learning objectives related to circuit analysis in addition to placing the learning in context of a real-world engineering system. However, further studies will need to be conducted to evaluate the effects of this approach on student's AC steady state circuit analysis skills and to better understand how or if the method effects student motivation related to learning.

\section{References}

[1] C. Munson, "Elements of a new electrical engineering curriculum at Illinois: a shift from circuits to signal processing," Proc. IEEE Symp. Circuits and Systems, Vol. 2, pp. 1Sf2Sf., 1995. https://doi.org/10.1109/iscas.1995.521434

[2] L. Huettel, A. Brown, L. Collins, K. Coonley, M. Gustafson, J. Kim, and G. Ybarra, "A novel introductory course for teaching the fundamentals of electrical and computer engineering”. Proc. ASEE Ann. Conference \& Exposition, 2006.

[3] J. Song, M. Xiaoyan, X. Huihui, and M. Yoder, "Learning and practicing fundamentals of electrical and computer engineering through building and programming a microcontroller with multiple peripherals", Proc. IEEE Frontiers in Education Conference, pp. S2F-1 S2F-6, 2010. https://doi.org/10.1109/fie.2010.5673231

[4] F. J. Mercede, "Hands-on projects to introduce Electrical and Computer Engineering," Proc. IEEE Frontiers in Education Conference, pp. F1F-9-F1F-14, 2008

[5] B.M. Olds and R.L. Miller, "The effect of a first-year integrated engineering curriculum on graduation rates and student satisfaction: a longitudinal study," J. Engineering Education, vol. 93.1, pp. 23-36, 2004. https://doi.org/10.1002/j.2168-9830.2004.tb00785.x

[6] J. B. Schodorf, M. A. Yoder, J. H. McClellan and R. W. Schafer, "Using multimedia to teach the theory of digital multimedia signals," in IEEE Transactions on Education, vol. 39, no. 3, pp. 336-341, 1996. https://doi.org/10.1109/13.538756

[7] J.W. Nilsson, and S. A. Ridel. Electric Circuits. Upper Saddle River, NJ: Pearson/Prentice Hall, 2000.

[8] R.L. Boylestad, Introductory Circuit Analysis, $7^{\text {th }}$ ed. Englewood Cliffs, NJ: Prentice Hall, 1994.

[9] N. Fredetteand and J. Lochhead. "Student conceptions of simple circuits," Physics Teacher, vol. 18.3, pp. 194-98, 1980. https://doi.org/10.1119/1.2340470

[10] C. Von Rhöneck and K. Grob. "Representation and problem-solving in basic electricity, predictors for successful learning," Proc. Second International Seminar Misconceptions and Educational Strategies in Science and Mathematics, vol. 3, 1987. 
[11] R. Cohen., B. Eylon, and U. Ganiel. "Potential difference and current in simple electric circuits: A study of students' concepts," American Journal of Physics, vol. 51.5, pp. 407412, 1983. https://doi.org/10.1119/1.13226

[12] P. Vetter Engelhardt, and R. J. Beichner. "Students' understanding of direct current resistive electrical circuits," American Journal of Physics, vol. 72.1, pp. 98-115, 2004. https://doi.org/10.1119/1.1614813

[13] P. Brna. "Confronting misconceptions in the domain of simple electrical circuits," Instructional Science, vol. 17.1, pp. 29-55, 1988. https://doi.org/10.1007/BF001 $\underline{21233}$

[14] J. Bernhard and A.K. Carstensen, "Learning and teaching electrical circuit theory". Proc. PTEE 2002: physics teaching in engineering education, pp. 163-178, 2002.

[15] L.C. McDermott, and P.S. Shaffer, "Research as a guide for curriculum development: an example from introductory electricity. Part I: Investigation of student understanding" American Journal Of Physics, vol. 60(11), pp. 994-1013,1997 https://doi.org/10.1119/ $\underline{1.17003}$

\section{$7 \quad$ Authors}

M. J. Turner is with the Electrical and Computer Engineering Technology Department, Purdue University, New Albany, IN 47150, (MattTurner@Purdue.edu).

Article submitted 15 November 2016. Published as resubmitted by the author 12 January 2017. 